\title{
Road safety advocacy - a legitimate role for occupational therapists?
}

\author{
"Occupational therapy is a visionary discipline. Occupational injus- \\ tice is our most ambitious enterprise, and advocacy is one of its \\ key strategies:220.
}

So said Bonnie Kirsh when she gave the Muriel Driver Memorial Lecture in Canada in 20I5. She asserted that advocacy is a professional imperative for occupational therapists and that if we hope to foster meaningful occupation on a wide scale we must embrace our political and social responsibilities.

My research in the Johannesburg minibus taxi industry highlights that safe mobility is a socio-political issue, being a prerequisite for occupational participation and accessing healthcare, even for voting. The South African road traffic system has the potential to reduce the lingering spatial realities of apartheid, enable meaningful occupation, realise the human rights enshrined in our Constitution and help us meet the UN's Sustainable Development Goals. Instead, it is crashogenic - a term I have coined to describe how physical, legal, sociocultural and political factors together create a high likelihood of road traffic injuries and deaths.

South Africa is not alone in facing a public health crisis of road traffic injuries and deaths. More than I.3 million people die on the world's roads every year, akin to wiping out the population of a small country like Swaziland. Another 50 million people - equivalent to $90 \%$ of our own population - sustain injuries, many causing lifelong disability. However, our roads are amongst the most dangerous in the world, with 25 out of every 100000 South Africans dying in road crashes when the international average is 17 per 100000 and some countries (notably the UK, Australia and Scandinavia) have rates below 5 per 100000 . Despite our being a signatory to the United Nations Decade of Action for Road Safety 20 I I-2020 and having a well-funded lead agency (the Road Traffic Management Corporation) we are not on track to achieving our own modest goals for improvement, let alone the more ambitious Decade of Action goal of a $50 \%$ reduction in road fatalities by 2020 . Numerous people die and become disabled on our roads every day, with the picture at its worst during the "festive" season. Clearly, there is a need for urgent action. But where do occupational therapists fit in?

The WFOT Congress in Cape Town in May 2018 offered some clues. Its theme, "Connected in diversity: positioned for impact", was beautifully bookmarked by opening and closing keynote speakers Elelwani Ramugondo and Karen Whalley-Hammell, both of whom exhorted us to beware the narrowness of over-individualised practice and engage in broader advocacy work. Many congress presenters described advocacy work with groups experiencing occupational injustice and deprivation, including people displaced by civil conflict, migration and natural disasters, the homeless, the jobless and the socially excluded. The theme of our own OT Week in October, "Leadership, Advocacy and Collaboration for Transformation", created a further focus on advocacy, the need for which has already been highlighted in the literature. Clearly, our profession is stepping into socio-political roles which were unheard of - indeed, frowned upon - when many of us did our undergraduate training at the height of apartheid. For instance, a guest editorial by Elvin Williams, Lebogang Maseko and Helen Buchanan in this journal highlighted the need for rehabilitation advocacy to avert situations like the botched Life Esidimeni psychiatric deinstitutionalisation process, which resulted in patient deaths.

The purpose of road safety advocacy is to prevent death and injuries and ensure safe mobility, particularly for vulnerable road users like children, the elderly, people with disabilities and public transport users. Thus, it fits well within an occupational therapy frame of reference. That it is not yet a visible part of our profession may be because, as noted by Carlisle, it is difficult to go beyond case advocacy and embrace cause advocacy. Yet, who better to advocate for preventing road-related disability and promoting safe mobility than we as occupational therapists? Being at the coalface of postcrash care when it comes to rehabilitation and long-term support for clients and families, we know only too well the devastating effects of road injuries. We also know the biopsychosocial demands associated with safe driving - indeed, globally we are at the forefront of driver fitness evaluation, driving rehabilitation and adaptive driving. Arguably, our knowledge base thus gives us a professional duty to be road safety advocates.

To tap the level of support for this notion, during OT Week 2018, I surveyed OTASA members and was excited to find that three quarters of the 67 respondents viewed road safety advocacy as a legitimate role for occupational therapists. Many reported that their caseloads include road crash survivors (up to $75 \%$, in some cases) and more than half expressed interest in becoming involved in this sphere of work, either actively or passively (for instance, as donors). About $60 \%$ reported that they seldom or never discuss road safety with clients, families or employers, mainly due to inadequate knowledge and thereby indicated a need for workshops and online courses on road safety legislation and best practice, as well as access to road safety data and road safety materials.

South African occupational therapists, with our depth of development and well-established professional structures and training centres, are well-placed to become global pioneers in road safety advocacy. This would be a fitting response to our own crashogenic road traffic system and unacceptable levels of road-related disability. It would also carve a niche for our profession in relation to contemporary road safety strategies like the Safe Systems approach.

In the words of Williams et $\mathrm{al}^{8}$, it's time to act.

\section{ACKNOWLEDGEMENTS}

Acknowledgements to my PhD supervisors, Assoc Prof Kevin Behrens and Prof Ames Dhai (Steve Biko Centre for Bioethics, University of the Witwatersrand). Grateful thanks to the Crouch Trust for two consecutive research grants.

\section{REFERENCES}

I. Williams E, Maseko L, Buchanan H. Rehabilitation - strengthening advocacy for change. It's time to act. Guest editorial. SAJOT. 2017; 47(3):2.

2. Carlisle S. Health promotion, advocacy and health inequalities: a conceptual framework. Health Prom International. 2000. 15:369376. DOI: 10.1093/heapro/I5.4.369.

3. Randall L. What do occupational therapists think about road safety advocacy? 2018. Focus. Vol 2 (in press).

Lee Randal

BSc Occ. Ther. (Wits), MA (Tufts), Dip (Voc. Rehab), Cert (Med \& Law) Occupational therapist in private practice PhD student, Steve Biko Centre for Bioethics, University of the Witwatersrand 